\title{
IMPLICATIONS OF LONG-LASTING INSECTICIDE-TREATED BED NETS (LLINs) FOR MALARIA CONTROL AND PREVENTION IN SOMALIA
}

\author{
${ }^{* 1}$ Omar, A. S., ${ }^{2}$ Son, B. \& ${ }^{3}$ Wambalaba, F.
}

\author{
${ }^{*}$ Senior WASH Strategic Policy Advisor, Ministry of Energy and Water Resources, Federal Government of Somalia \\ ${ }^{2}$ Business and Sustainable Management, Anaheim University, Anaheim, CA, USA \\ ${ }^{3}$ United States International University, Kenya, Nairobi, Kenya \\ *Corresponding Author's E-mail: dr.abdiqani@ hotmail.com Phone: +252 615577282 (Somalia) | +254702727358 (Kenya)
}

\begin{abstract}
$\mathrm{I}$

n Sub-Saharan Africa, bed nets are mainly aimed at the prevention of the nuisance of mosquito biting rather than against malaria. The species that are involved in malaria infection are all present in Somalia with the leading one being Plasmodium falciparum that causes about $98 \%$ of all infections in the country. This alarming spread of malaria underscores the need to develop interventions that can effectively curb the malaria menace. This study sought to examine the implications of the utilization of long-lasting insecticide-treated bed nets (LLINs) for malaria control and prevention. The population constituted 1,100 pregnant women attending $\mathrm{MCH}$ clinics and the two thousand two hundred heads of households, totaling three thousand three hundred. A simple random sampling technique was used to obtain a representative sample of households. In surveying 110 pregnant women attending Maternal Child Health $(\mathrm{MCH})$ clinics and 220 heads of households in the Belet Hawo district in Somalia in 2019, the study found that the majority of households knew the effect of LLINs on preventing malaria. They were also knowledgeable about how to control malaria while facing limited access to LLINs. Furthermore, LLIN usage helped households to raise awareness and knowledge about the effect of LLINs on preventing malaria. This study provided the Somalian government with a better understanding of the causes, control, and prevention of malaria.
\end{abstract}

Keywords: Malaria Control, Malaria Prevention, Somalia, Long-lasting Insecticidal Nets

LICENSE: This article by African Journal of Health, Safety and Environment (AJHSE) is licensed and published under the Creative Commons Attribution License 4.0 International License, which permits unrestricted use, distribution, and reproduction in any medium, provided this article is duly cited.

COPYRIGHT: The Author(s) completely retain the copyright of this published article.

OPEN ACCESS: The Author(s) approves that this article remains permanently online in the open access (OA) model

QA: This Article is published in line with "COPE (Committee on Publication Ethics) and PIE (Publication Integrity \& Ethics)". 


\section{INTRODUCTION}

Malaria is a life-threatening disease that is transmitted through an anopheles mosquito that carries the plasmodium parasite (Anandet al., 2018). Malaria has been ranked as a world health major catastrophe as the parasites that transmit the disease are found in almost half of the world's habitat. In semi-arid and highland regions of Africa, malaria is an epidemic and causes deaths annually (Blanford et al., 2013). However, the risks of morbidity and mortality associated with malaria, particularly in semi-arid and highland regions vary spatially and temporally (Snow and Marsh, 2010). Most malaria infections, particularly in sub-Saharan Africa, are caused by Plasmodium falciparum. Malaria presents a major socio-economic challenge to African countries thatare the most affected region in the world. This challenge cannot go unnoticed given that good health is not only a basic human need but also a prerequisite for economic growth (WHO, 2018). Malaria is known to affect the growth of children by causing abnormalities like intellectual development capability which lowers the productivity of an individual in the workplace (Greenwood et al., 1991).

The species Plasmodium that causes malaria infection is all present in Somalia with the leading one being Plasmodium falciparum that causes about $98 \%$ of all infections in the entire country (Autino et al., 2012). Nearly 95\% of the population in the South Central of Somalia lives in malaria-endemic areas. Since 2007, approximately 2 million long-lasting insecticide-treated bed nets (LLINs) have been distributed in Somalia, and most of the distribution occurred in the Central South Zone where the burden of malaria is highest. Gedo is one of the regions with the highest malaria transmission intensity in Somalia.

A malaria indicator survey in 2014 in Somalia showed low levels of ownership (19\%) and use (20\%) of LLINs. Although the survey was the first of its kind in Somalia, it was undertaken under challenging logistical demands and standard sampling requirements were not always met. Furthermore, detailed qualitative investigations by key informants and through focused group discussions were not undertaken. Households' access to malaria information and understanding the use of transmission of malaria were also inadequate (Puntland Statistics Department, 2017). Meanwhile, there are still no detailed studies on knowledge, attitudes, and practices and their

effect on the use of LLINs in the Gedo region despite having the highest malaria transmission intensity with a high human population movement. Hence, this study was carried out to understand the level of ownership, rates of the use of LLINs, and the knowledge and awareness of the effect of LLINs in malaria prevention in the Belet Hawo district of the Gedo region. Accordingly, the purposes of the study are threefold to determine the ownership of LLINs among households, to investigate the usage of LLINs among households, and to assess the knowledge level about the effect of LLINs on preventing malaria in the Belet Hawo district. The study helps to improve malaria messaging for LLINs in the South Central region, which further promotes prevention and vector control strategies for achieving the goals of the National malaria control and elimination program. In the next section, we describe the methods of our survey and then discuss the results and implications of our findings for policymakers to take stringent measures to curb any future spread of this pandemic. 


\section{MATERIALS AND METHODS}

A descriptive research design was used to assess the current ownership and utilization of LLINs among household members in the Belet Hawo district and to determine reasons, barriers, and behaviors towards the use of LLINs. In this study, the population constituted 1,100 pregnant women attending MCH clinics and 2,200 heads of households, totaling 3,300. Simple random sampling technique was used to obtain a representative sample of households. According to the 10 percent rule in statistics, sample sizes should be no more than 10 percent of the population. Hence, the study had a sample size of 330 which represented 10 percent of the study population which is enough to generalize the study findings (Nardi, 2018). That is, 110 pregnant women attending MCH clinics and 220 heads of households in Belet Hawo district constituted the sample and were surveyed during the period from January to September 2019.

Structured close-ended questionnaires were employed to gather information over a large sample using a drop and pick up method for the survey respondents. A proposal was presented to the Institutional Review Board of the Ministry of the Health and Human Services, Somalia for approval to conduct the study among the households in the Belet Hawo district. Households could consent to participate in the study and were assured of confidentiality. To ensure content validity, questionnaires were examined by the two independent managers who were the director of Public Health and the manager at Malaria Department Unit at the Ministry of Health and Human Service. They identified any flaw in the design or logic. To test for reliability, the survey data was split into two and the findings of the two data sets were compared to check for variance in the results. In this study, reliability was determined using the Cronbach alpha method for internal consistency. The reliability and trustworthiness of the data collected revealed a coefficient Cronbach alpha $=0.70$. Out of all the 330 questionnaires administered, the total number of returned questionnaires was 300, hence the response rate was $91 \%$. Data were coded, entered, and analyzed to compute descriptive statistics using the Statistical Package for Social Sciences (SPSS) version 21.0.

\section{RESULTS AND DISCUSSION}

There were more females than males in the survey with $216(65.45 \%)$ and 114 (34.55\%) respectively as some households were headed by females who were either widowed or single mothers. The age distribution indicated almost $87 \%$ of the respondents in the 20 to 59 years age group, while showing the 71 percent of respondents without a high school diploma. Table 1 shows the findings of the knowledge level about the effect of LLINs on preventing malaria. We interviewed the knowledge level on a Likert scale of 1 to 5, where 1: Strongly agree (SA), 2: Agree (A), 3: Disagree (D), 4: Strongly disagree (SD), and 5: not applicable (NA). Overall, the study found that most households were having a high level of knowledge about the effect of LLINs on preventing malaria. The surveyed households strongly agreed that "Prevention of disease through better awareness is the appropriate way to prevent the disease" with the highest mean of 4.44. Respondents also agreed that "People are knowledgeable about malaria disease with the mean" of 4.32, "Women delay in seeking for health services" with the mean of 4.29, and "Limited financial capacity causes a lack of malaria prevention" with the mean of 4.28. Contrary to women who delay in seeking health services, the households agreed that "Men are usually first in seeking health care" with the mean of 4.18. These results revealed the reasons why households, where men were the head of the houses, had access to treated mosquito nets as compared to houses that were headed by women. Furthermore, the households agreed that "Insecticide fumigation has 
an impact on the socioeconomic status of households" with the mean of 3.88 and "Prevention of disease through the use of LLINs is the appropriate way to prevent the disease" with a mean of 3.75.

The results of the extent of LLIN ownership among households are summarized in Table 2. The households agreed that "There is free delivery of LLINs to MCH clinics to prevent pregnant women from malaria" with the mean of 4.18 and some of them agreed that "there is free delivery of LLINs through mass campaigns" with the mean of 3.44. Meanwhile, households strongly agreed that "I have had malaria" with the mean of 4.34 and also "My household member had malaria" with the mean of 4.28. Since LLINs are delivered to pregnant women and newborn babies for free either through mass campaigns or routinely in $\mathrm{MCH}$ clinics, accessing treated mosquito nets poses a serious challenge to households without pregnant mothers attending $\mathrm{MCH}$ clinics while living below a dollar in a day. Some of the interviewed households confessed that they knew people in their villages that died from malaria, which was mainly caused by not using LLINs. The findings signified implications of the limited distribution of LLINs in the high malaria-endemic region although some households agreed that ' $I$ have been exposed to health education about malaria' with the mean of 3.76 .

Findings from this study further revealed challenges of implementing the usage of LLINs although the households agreed that "The use of LLINs has been the main approach to vector control in most areas of the country" with mean of 4.28 (Table 3). One major challenge encountered in the implementation of the use of LLINs is overpopulated households whose members face a cumbersome issue associated with LLIN ownership. Since not every household can afford LLINs, the spread of malaria continues while LLINs remain one of the most effective interventions against malaria. Subsequently, the households agreed that "the community uses traditional methods of treating malaria disease instead of going to the hospital" with mean of 3.77, while some of them agreed that "better health care is related to economic problems" with mean of 3.44, and "ignorance causes an increased rate of malaria infection" with mean of 3.14. Overall, the study found that the majority of households knew the effect of LLINs on preventing malaria. They were also knowledgeable about how to control malaria while facing limited access to LLINs. Respondents knew how to control malaria by clearing bushes around them, removing water loggings to destroy breeding places of mosquitos, and sleeping under treated mosquito nets even though there was no fair distribution of LLINs. It was also found that LLIN usage among households was seen creating awareness and knowledge about the effect of LLINs on preventing malaria.

This study examined the knowledge level and practice among the households regarding malaria prevalence, prevention, and the current treatment regime in one of the highest malaria transmission areas in Somalia. Most households were knowledgeable about preventing malaria disease, but their biomedical treatment was constrained due to limited financial capacity. The limited capacity for biomedical treatment has implications for issues of affordability and availability. In his study on people's perception of malaria in Mbarara, Uganda, Nuwaha (2002) recommended that people should be educated on the link between mosquitoes and malaria and seeking biomedical treatment for convulsions. It is critical that policymakers and practitioners closely review the current malaria problems and mitigation strategies. 
Table 1: Knowledge Level About the Effect of LLINs On Malaria Prevention

\begin{tabular}{|c|c|c|c|c|c|c|c|}
\hline \multirow{2}{*}{$\begin{array}{l}\text { Knowledge Level about Effect of LLINs } \\
\text { in Malaria Prevention }\end{array}$} & $\mathbf{S A}$ & $\mathbf{A}$ & $\mathbf{D}$ & SD & $\mathbf{N A}$ & Mean & St.Dev \\
\hline & 1 & 2 & 3 & 4 & 5 & $\mathrm{X}$ & SD \\
\hline $\begin{array}{l}\text { You are knowledgeable about the effect of } \\
\text { LLINs on malaria prevention. }\end{array}$ & 82 & 79 & 41 & 48 & 80 & 3.76 & 0.21 \\
\hline $\begin{array}{l}\text { People are knowledgeable about malaria } \\
\text { disease. }\end{array}$ & 81 & 81 & 40 & 58 & 70 & 4.32 & 0.23 \\
\hline $\begin{array}{l}\text { Limited financial capacity causes a lack of } \\
\text { malaria prevention. }\end{array}$ & 80 & 74 & 47 & 50 & 79 & 4.28 & 0.19 \\
\hline $\begin{array}{l}\text { Men are usually the first in seeking health } \\
\text { care. }\end{array}$ & 82 & 72 & 49 & 51 & 76 & 4.18 & 0.20 \\
\hline Women delay in seeking health services. & 72 & 82 & 51 & 48 & 77 & 4.29 & 0.17 \\
\hline $\begin{array}{l}\text { Men are less willing when it comes to } \\
\text { spending towards the health of their } \\
\text { children. }\end{array}$ & 80 & 81 & 41 & 48 & 80 & 4.24 & 0.25 \\
\hline $\begin{array}{l}\text { Prevention of disease through better } \\
\text { knowledge is an appropriate way to prevent } \\
\text { the disease. }\end{array}$ & 78 & 83 & 41 & 47 & 81 & 3.80 & 0.23 \\
\hline $\begin{array}{l}\text { Prevention of disease through better } \\
\text { awareness is the appropriate way to prevent } \\
\text { the disease. }\end{array}$ & 81 & 81 & 40 & 58 & 70 & 4.44 & 0.16 \\
\hline $\begin{array}{l}\text { Insecticide fumigation has an impact on the } \\
\text { socioeconomic status of households }\end{array}$ & 85 & 81 & 41 & 48 & 75 & 3.88 & 0.18 \\
\hline $\begin{array}{l}\text { Prevention of disease through the use of } \\
\text { LLINs is the appropriate way to prevent the } \\
\text { disease. }\end{array}$ & 76 & 85 & 41 & 47 & 81 & 3.75 & 0.21 \\
\hline $\begin{array}{l}\text { Successful malaria control program requires } \\
\text { sustainable political commitments. }\end{array}$ & 83 & 83 & 40 & 49 & 75 & 4.32 & 0.23 \\
\hline
\end{tabular}


Table 2: Determining the Extent of LLIN Ownership Among Households

\begin{tabular}{|c|c|c|c|c|c|c|c|}
\hline $\begin{array}{l}\text { Determining the extent of LLIN ownership } \\
\text { among households in Belet Hawo district }\end{array}$ & $\begin{array}{l}\text { SA } \\
1\end{array}$ & $\begin{array}{l}\mathbf{A} \\
2\end{array}$ & $\begin{array}{l}\text { D } \\
3\end{array}$ & $\begin{array}{l}\text { SD } \\
4\end{array}$ & $\begin{array}{l}\text { NA } \\
5\end{array}$ & $\begin{array}{l}\text { Mean } \\
X\end{array}$ & $\begin{array}{l}\text { St.Dev } \\
\text { SD }\end{array}$ \\
\hline $\begin{array}{l}\text { There is free delivery of LLINs through mass } \\
\text { campaigns. }\end{array}$ & 82 & 72 & 49 & 51 & 76 & 3.44 & 2.17 \\
\hline $\begin{array}{l}\text { There is free delivery of LLINs to MCH clinics } \\
\text { to prevent pregnant women from malaria. }\end{array}$ & 72 & 82 & 51 & 48 & 77 & 4.18 & 2.23 \\
\hline $\begin{array}{l}\text { High temperatures normally result in low } \\
\text { breeding of mosquitoes which helps in reducing } \\
\text { cases of malaria infection. }\end{array}$ & 80 & 81 & 41 & 48 & 80 & 4.29 & 2.22 \\
\hline Malaria is a risk in my area. & 78 & 83 & 41 & 47 & 81 & 3.88 & 2.19 \\
\hline $\begin{array}{l}\text { I have been exposed to health education about } \\
\text { malaria. }\end{array}$ & 81 & 81 & 40 & 58 & 70 & 3.76 & 2.20 \\
\hline I have had malaria myself. & 85 & 81 & 41 & 48 & 75 & 4.34 & 2.15 \\
\hline My household member had malaria in the past. & 76 & 85 & 41 & 47 & 81 & 4.28 & 2.12 \\
\hline $\begin{array}{l}\text { I know of someone in my village that died from } \\
\text { malaria in the past. }\end{array}$ & 80 & 74 & 47 & 50 & 79 & 3.88 & 2.14 \\
\hline
\end{tabular}

Table 3: Investigating the Levels of LLIN Usage

\begin{tabular}{|c|c|c|c|c|c|c|c|}
\hline $\begin{array}{l}\text { Investigating the levels of LLIN usage among } \\
\text { households in Belet Hawo district }\end{array}$ & $\begin{array}{l}\text { SA } \\
1\end{array}$ & $\begin{array}{l}\text { A } \\
2\end{array}$ & $\begin{array}{l}\mathbf{D} \\
3\end{array}$ & $\begin{array}{l}\text { SD } \\
4\end{array}$ & $\begin{array}{l}\text { NA } \\
5\end{array}$ & Mean & St.Dev \\
\hline $\begin{array}{l}\text { The use of long-lasting insecticidal nets (LLINs) } \\
\text { has been the main approach to vector control in } \\
\text { most areas of the country. }\end{array}$ & 80 & 74 & 47 & 50 & 79 & 4.28 & 2.88 \\
\hline $\begin{array}{l}\text { Good health has a positive and significant effect on } \\
\text { economic growth. }\end{array}$ & 78 & 76 & 47 & 50 & 79 & 3.22 & 2.52 \\
\hline $\begin{array}{l}\text { Ignorance causes an increased rate of malaria } \\
\text { infection. }\end{array}$ & 80 & 74 & 49 & 51 & 76 & 3.14 & 2.48 \\
\hline $\begin{array}{l}\text { Children living in crowded dwellings are infected } \\
\text { with malaria more frequently than other children } \\
\text { living in better housing conditions. }\end{array}$ & 70 & 84 & 51 & 48 & 77 & 2.89 & 2.19 \\
\hline $\begin{array}{l}\text { Children living in poor quality housing are infected } \\
\text { with malaria more frequently than other children } \\
\text { living in better housing conditions. }\end{array}$ & 80 & 81 & 41 & 48 & 80 & 3.06 & 2.28 \\
\hline $\begin{array}{l}\text { The community uses traditional methods of treating } \\
\text { malaria disease instead of going to the hospital. }\end{array}$ & 81 & 81 & 40 & 58 & 70 & 3.77 & 2.77 \\
\hline
\end{tabular}


This study found that limited LLIN ownership for households with earnings below a dollar a day imposes challenges in the implementation of the use of LLINs which has been the main approach to vector control in most areas of Somalia. To foster the acceptance of LLINs, communication efforts should be mobilized within the framework of a malaria control program (Seidel et al., 2012). Furthermore, barriers, such as the high cost of nets that influenced negatively the control program, should always be considered when implementing interventions. The African Summit on Roll Back Malaria in 2000 launched multifaceted malaria control strategies, including expanded coverage of insecticide-treated nets, which contributed to a 68\% decline in malaria morbidity in Africa between 2000 and 2015 (Bhatt et al., 2015). While the progress on malaria control has been made partly through growing international financing, uneven coverage of insecticide-treated nets has been persisting as this study affirmed. The WHO (2017) recommended universal coverage of LLINs through mass distribution of free nets through campaigns, antenatal care clinics, and immunization. In Somalia, LLINs are commonly distributed among internally displaced persons and in focal areas in response to epidemics.

The findings from this study showed that children living in crowded neighborhoods are infected with malaria more frequently compared to children living in better housing conditions, which signifies the link between malaria control and housing condition, a manifestation of socioeconomic position. The aforementioned results also indicated the effect of poverty on LLIN ownership. Hence, the government of Somalia should explore multisectoral malaria control strategies given the relationships between malaria disease, LLIN ownership, and socioeconomic position. Accordingly, multisectoral interventions against malaria require coordination with anti-poverty programs, housing improvement, and mobilization of adequate national and international human and financial resources (Trusting et al., 2016). However, significant challenges affecting the availability of these critical resources in Somalia are exacerbating the healthcare crisis including a high risk of epidemic-prone and communicable diseases (WHO, 2015).

\section{CONCLUSION}

This study evaluated the ownership of LLINs at a household level, their appropriate use by the household members, and the knowledge and awareness of the role of LLINs in malaria prevention in the Belet Hawo district of Gedo region, Somalia. The study found that male patients who had malaria did not want to be treated by female doctors, and the women patients were also not free to be examined by male health practitioners because of the Somali culture. A further study should be done on cultural differences hindering the treatment of patients by the opposite gender in fear of going against their cultural practices and beliefs. The result of the study will be used to improve malaria awareness for LLINs in the South Central region. The study is of importance to the community, and the National and County governments of Somalia republic as it provides a better understanding of the causes, control, and prevention of malaria.

This will help the Ministry of Health to develop and implement vector control strategies to achieve the objectives and goals of the national malaria control and elimination program. The study may also be used by humanitarian aid organizations working in Somalia by revealing the factors affecting ownership and utilization of LLINs among families for malaria control and prevention in the Belet Hawo district. 


\section{ACKNOWLEDGMENTS}

The Ministry of the Health and Human Services, Somalia is gratefully acknowledged for approval to conduct the study among the households in Belet Hawo district.

\section{CONFLICT OF INTERESTS}

The authors declare that they have no conflicts of interest.

\section{REFERENCES}

Anand, C., Sharma, R., and Mishra, K. N. (2018). Assessment of malarial fever in children by estimation of haematological profile. International Journal of Medical and Health Research, 4(10): 196-198.

Bhatt, S., Weiss, D. J., Cameron, E., Bisanzio, D., Mappin, B., Dalrymple, U., Battle, K., Moyes, C. L., Henry, A., Eckhoff, P. A., Wenger, E. A., Briët, O., Penny, M. A., Smith, T. A., Bennett, A., Yukich, J., Eisele, T. P., Griffin, J. T., Fergus, C. A., Lynch, M., Lindgren, F., Cohen, J. M., Murray, C. L. J., Smith, D. L., Hay, S. I., Cibulskis, R. E., and Gething, P. W. (2015). The effect of malaria control on Plasmodium falciparum in Africa between 2000 and 2015. Nature, 526(7572): 207-211. doi: 10.1038/nature15535.

Blanford, J., Blanford, S., Crane, R., Mann, M., Paaijmans, K., Schreiber, K., and Thomas, M. (2013). Implications of temperature variation for malaria parasite development across Africa. Scientific Reports, 3(1300): 1-11. doi: 10.1038/srep01300.

Greenwood, B. M., Marsh, K. and Snow, R. W. (1991). Why do some African children develop severe malaria? Parasitol Today, 7(10): 277-281. doi: 10.1016/0169-4758(91)90096-7.

Nardi, P. M. (2018). Doing survey research: A guide to quantitative methods. New York, Routledge, 272pp.

Puntland Statistics Department (2017). The First Malaria Indicator Survey in Somalia, 2014. Zonal NMCPs/MOHs of the Federal Government, Puntland and Somaliland. Retrieved on $7^{\text {th }}$ December, 2020 from: http://pl.statistics.so/wp-content/uploads/2017/06/1_Som_MIS-2014_220416.pdf.

Qayad, M. G. (2007). Health care services in transitional Somalia: challenges and recommendations. Bildhaan: an International Journal of Somali Studies, 7(10): 190-210.

Seidel, R. Thaddeus P., Kovach, T., Kim, P., Divine, B., Alilio, M., Koenker, H., Waisbord, S., Smith, P., and Cho, P. (2012). The Strategic Framework for Malaria Communication at the Country Level 2012-2017. The Roll Back Malaria Partnership. Geneva: World Health Organization, 60pp. Retrieved on 1st December, 2020 from: https://healthmarketinnovations.org/sites/default/files/The\%20Strategic\%20Framework\%20for\%20Malari a\%20Communication\%202012rr.pdf 
Snow, R. W. and Marsh, K. (2010). Malaria in Africa: progress and prospects in the decade since the Abuja Declaration. The Lancet, 376(9735): 137-139. doi: 10.1016/S0140-6736(10)60577-6.

Tusting, L. S., Rek, J., Arinaitwe, E., Staedke, S. G., Kamya, M. R., Cano, J., Bottomley, C., Johnston, D., Dorsey, G., Lindsay, S. W., and Lines, J. (2016). Why is malaria associated with poverty? Findings from a cohort study in rural Uganda. Infectious diseases of poverty, 5(1): 78. doi:10.1186/s40249-016-0164-3.

WHO. (2015). Strategic review of the Somali health sector: challenges and prioritized actions. Nairobi: WHO Somalia, 44pp.

WHO. (2017). Achieving and maintaining universal coverage with long-lasting insecticidal nets for malaria control. Geneva: World Health Organization, 4pp. Retrieved on 20th November, 2020 from: https://www.who.int/malaria/publications/atoz/who_recommendation_coverage_llin/en/

WHO (2018). A VISION FOR PRIMARY HEALTH CARE IN THE 21ST CENTURY: Towards universal health coverage and the sustainable development goals. Geneva: World Health Organization, 64pp. Retrieved on $23^{\text {rd }}$ October, 2020 from: https://www.who.int/docs/default-source/primary-health/vision.pdf 